\title{
Correction to: Realizing drug repositioning by adapting a recommendation system to handle the process
}

Makbule Gulcin Ozsoy ${ }^{1}$, Tansel Özyer ${ }^{2}$, Faruk Polat ${ }^{1}$ and Reda Alhajj ${ }^{3^{*}}$

\section{Correction}

Following publication of the original article [1], the authors reported that there was an error in the spelling of the name of one of the authors.

Originally the author's name was spelled as:

Makbule Guclin Ozsoy

The correct spelling is:

Makbule Gulcin Ozsoy

\section{Author details}

'Department of Computer Engineering, Middle East Technical University,

Ankara, Turkey. ${ }^{2}$ Department of Computer Engineering, TOBB University,

Ankara, Turkey. ${ }^{3}$ Department of Computer Science, University of Calgary,

Calgary, AB, Canada.

Accepted: 21 June 2018

Published online: 02 July 2018

\section{Reference}

1. Ozsoy MG, et al. Realizing drug repositioning by adapting a

recommendation system to handle the process. BMC Bioinformatics. 2018;

19:136. https://doi.org/10.1186/s12859-018-2142-1. 